\title{
Dietary and age influences on bone health indices in pre-menopausal Brazilian women: preliminary results of the D-SOL Study
}

\author{
M.M. Mendes ${ }^{1}$, K. Hart ${ }^{1}$, P.B. Botelho ${ }^{2}$, L. Tripkovic ${ }^{1}$, S.L. Wilson-Barnes ${ }^{1}$, P.S. Gibson ${ }^{1}$, \\ R.J. Manders ${ }^{1}$, J. Wainwright ${ }^{1}$ and S.A. Lanham-New ${ }^{1}$ \\ ${ }^{1}$ Department of Nutritional Sciences, Faculty of Health and Medical Sciences, University of Surrey, Guildford, Surrey, \\ $U K$, GU2 $7 X H$ and \\ ${ }^{2}$ Faculty of Nutrition, Federal University of Goiás, GO, Brazil
}

To date, there are still limited data available for pre-menopausal women on the effect of aging and diet on bone health. ${ }^{(1)}$ It is unclear whether younger women are at risk of poor bone health and to what extent diet and ethnicity should be considered as predictors. This preliminary analysis assessed habitual dietary intake and associations to bone health indices. This was a cross-sectional analysis of 50 Brazilian women recruited for the D-SOL study. Radial bone geometry and density were measured using peripheral quantitative computed tomography at diaphyseal $(66 \%)$ and distal $(4 \%)$ sites. Weight and body fat were measured using a Tanita Body Composition Analyser. Nutrient intakes were assessed by $4 \mathrm{~d}$ diet diaries.

The average age, weight, BMI and body fat of the participants were $34 \cdot 1 \pm 8 \cdot 1$ years, $70 \cdot 1 \pm 14 \cdot 1 \mathrm{~kg}, 26 \cdot 1 \pm 5 \cdot 2 \mathrm{~kg} / \mathrm{m}^{2}$ and $30 \cdot 8 \pm 5 \cdot 8$ $\%$ respectively; no significant differences in weight, BMI and body fat were found between younger (Y: $\mathrm{n}=19,20-33$ years) and older women $(\mathrm{O}: \mathrm{n}=27,35-59$ years). For the cohort analysis as whole, weight was positively associated with mass at the $4 \%$ site $(p=0 \cdot 30)$ and total area at the $66 \%$ site $(p=0.006)$ and negatively for total bone density $(p=0.013)$ and cortical density at the $66 \%$ site $(p=0 \cdot 028)$. When comparing age groups, the older group $\left(41 \cdot 3 \pm 6 \cdot 7\right.$ years, BMI $\left.26 \cdot 9 \pm 5 \cdot 2 \mathrm{~kg} / \mathrm{m}^{2}\right)$ showed significant higher trabecular $(\mathrm{p}=0.009)$ and total $(\mathrm{p}=0.003)$ area at the $4 \%$ site, but significantly lower total density $(\mathrm{p}=0.15)$ at the same site, than the younger group $\left(28.5 \pm 3.2\right.$ years, BMI $\left.25 \cdot 3 \pm 5 \cdot 2 \mathrm{~kg} / \mathrm{m}^{2}\right)$. Older women also showed a significant positive association between age and mass $(p=0.015)$, total area $(p=0.037)$ and cortical area $(p=0.013)$ at the $66 \%$ site, whereas for the younger women there was a negative association between age and total density at $4 \%$ site $(p=0.034)$. A trend towards higher vitamin $D$ intakes was observed within the older women (O: $3.4 \pm 2.4 \mu \mathrm{g} / \mathrm{day}$; Y: $2.7 \pm 1.4 \mu \mathrm{g} /$ day) whilst calcium intakes were fairly similar between the groups (O: $738.7 \pm 234.5 \mathrm{mg} /$ day; Y: $738.76 \pm 372.1 \mathrm{mg} /$ day). At the $4 \%$ site, energy-adjusted vitamin D intakes were positively correlated to mass $(p=0.046)$; iron and vitamin $K$ intakes were positively correlated to trabecular density $(p=0.000)$. At the $66 \%$ site, energy-adjusted potassium $(p=0.043)$ and sodium $(p=0.040)$ intakes were positively correlated to total bone density. However, when divided by age, correlations were observed only for iron and trabecular density in both groups $(\mathrm{O}: \mathrm{p}=0.031 ; \mathrm{Y}: \mathrm{p}=0 \cdot 007)$, and for vitamin $\mathrm{K}$ and trabecular density only for younger women.

This indicates that age and diet can be of great influence on bone health for pre-menopause women and may be under-appreciated in younger populations as an important predictor or even preventive factor for osteoporosis. Cultural trends in diet, especially for ethnics groups living abroad where cultural dietary adaptation is required, may not reflect previous findings on native population. Taken together with intra-ethnic body composition variations, other non-dietary influences upon bone metabolism have an important role in bone health. In addition, vitamin D intake within these women was extremely low considering the new UK recommendations (RNI of $10 \mu \mathrm{g} / \mathrm{d}$ for the general population). ${ }^{(2)}$ A more thorough investigation to determine other influential factors on bone health is urgently required. The D-SOL Study will provide valuable insights from a public health perspective into the specific predictors and requirements for optimum bone health for this population.

MM is recipient of a Science Without Borders PhD Scholarship.

1. Hardcastle AC, Aucott L, Fraser WD et al. (2011) Eur J Clin Nutr 65, 378-385.

2. Scientific Advisory Committee on Nutrition (2016) Vitamin D and Health. London: The Stationary Office. 